\title{
Stress lass nach!
}

Technik macht heute vieles leichter. Niemand muss mehr neben einem Festnetztelefon sitzen, um erreichbar zu sein, Präsentationen kann man problemlos Menschen zeigen, die hunderte oder tausende Kilometer von einem entfernt sind und vieles mehr. Die Kehrseite der ständigen Erreichbarkeit, der ständigen Aufforderung zur Kommunikation, ist aber, dass sie Stress verursacht.

Dabei stellen sich zwei Fragen: Warum führt das überhaupt zu Stress? Und: Was kann man dagegen tun? Beides versuchen wir in diesem Themenschwerpunkt zu behandeln und zumindest in Ansätzen zu beantworten. Wer es schafft, den Stress durch Technik möglichst klein zu halten, kann von den unbestrittenen Vorteilen umso mehr profitieren.

Besonders wichtig erscheint dabei das bewusste Abschalten. Das war in Zeiten vor der Allgegenwart von mobiler Kommunikation automatisch gegeben. Wer nicht im Büro war, den konnte man nicht erreichen, er hatte Feierabend. Das wurde mit dem Siegeszug der Mobiltelefone anders und kippte vollends mit der zunehmenden Verbreitung der Smartphones. Auf einmal war das Büro (fast) überall und damit die Versuchung da, „nur mal eben schnell“ in die Mails zu schauen oder die aktuellen Verkaufszahlen abzurufen. Das hat im Idealfall sogar einen beruhigenden Effekt. Oft ist aber auch das Gegenteil der Fall.

Weil gerade E-Mails und Co. die unangenehme Eigenschaft haben, den ganzen Tag in großer Zahl in die Postfächer zu flattern, stellen sie eine ständige Ablenkung dar. Schlimmstenfalls ist der Betroffene nie mehr so ganz dort, wo er sich physisch befindet. Das bedeutet Stress für ihn selbst und kann zur Entfremdung von Familie und Freunden führen. Dem kann man sich nur durch gezielte Auszeiten wirklich entziehen. Manche Unternehmen verordnen diese sogar schon auf die „harte Tour“: Von zum Beispiel 18:00 bis 7:30 Uhr am

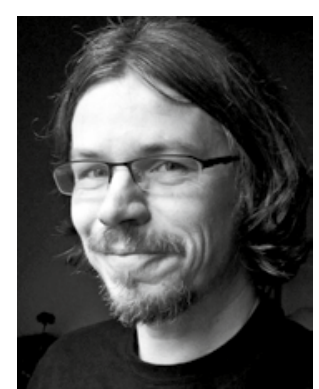

Peter Pagel

Chefredakteur

nächsten Morgen stellen sie den E-Mail-Server ab. Davon geht die Welt nicht unter und die Mitarbeiter bleiben gesünder das hofft man zumindest.

Wie meist, wenn sich neue Technik durchsetzt, passen sich die Verhaltensnormen der Gesellschaft erst mit einigem Nachlauf daran an. In diesem Prozess befinden wir uns gerade. Ich wünsche Ihnen gutes Gelingen bei der persönlichen digitalen Transformation.

Herzliche Grüße, Ihr

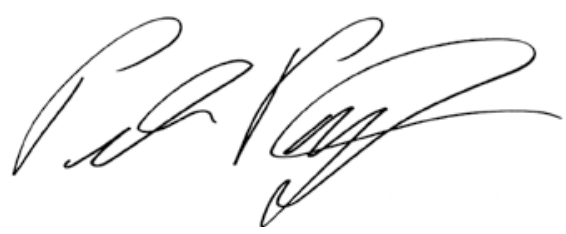

Peter Pagel 